\title{
Optimizing the bulk copolymerization of D,L-lactide and glycolide by response surface methodology
}

\author{
L. I. Cabezas, R. Mazarro, I. Gracia, A. de Lucas, J. F. Rodríguez* \\ Department of Chemical Engineering, Institute of Chemical and Environmental Technology University of Castilla-La \\ Mancha, Av. Camilo José Cela 12, 13071 Ciudad Real, Spain
}

Received 9 May 2013; accepted in revised form 11 July 2013

\begin{abstract}
Poly(D,L-lactide-co-glycolide), PLGA, is a biodegradable polyester with high interest in medical industry, especially when zinc (II) 2-ethylhexanoate $\left(\mathrm{ZnOct}_{2}\right)$ is used as catalyst substitute in polymerization processes as a substitute of the toxic tin (II) 2-ethylhexanoate ( $\left.\mathrm{SnOct}_{2}\right)$ together an initiator such as methanol to improve the reaction rate. This article shows the optimization of the bulk copolymerization method by using a factorial design approach on three experimental parameters: temperature $(T)$, molar ratio monomers/catalyst ( $M C$ ratio) and molar ratio initiator/catalyst (IC ratio). Their influence on mass conversion $(X)$ and number-average molecular weight $\left(M_{\mathrm{n}}\right)$ was also discussed. Also it provides a useful tool to select in a fast way the proper experimental conditions for the obtaining of this polymer as a previous stage in the synthesis and impregnation of biodegradable scaffolds. This analysis revealed that the most relevant variable in the process is the temperature, being desirable to use the high value $\left(160^{\circ} \mathrm{C}\right)$ in order to obtain high values of conversion and molecular weight.
\end{abstract}

Keywords: biodegradable polymers, poly(D,L-lactide-co-glycolide), bulk polymerization, optimization, response surface methodology

\section{Introduction}

Polylactide (PLA), polyglycolide (PGA) and their copolymer (PLGA) have been widely used as biomedical materials in absorbable sutures, orthopaedic devices, tissue scaffolds or drug delivery [1-3]. These types of biopolymers can be synthesized by direct melt polymerization of the hydroxyacids lactic and glycolic acid, as well as by ring-opening of the cyclic dimers lactide and glycolide (Figure 1). Ringopening polymerization (ROP) can take place by cationic, anionic, coordination-insertion or enzymatic mechanisms. The coordination-insertion method has drawn the most attention and has been widely employed due to advantages such as lower risk of side reactions, higher molecular weights obtained and easy control of the molecular weight $[4,5]$. Tin alkoxides and carboxylates have been usually used<smiles>CC1OC(=O)C(C)OC1=O</smiles>

Figure 1. Chemical structure of cyclic dimers: (a) lactide; (b) glycolide.

as catalysts for this mechanism, but the deposition of toxic metallic residues, difficult to extract, into the resulted polyesters becomes a severe drawback. This fact explains the success of zinc octoate, $\mathrm{ZnOct}_{2}$, as a substitute [5-7]. The mechanism consists in the conversion of $\mathrm{ZnOct}_{2}$ into zinc alkoxide by reaction with an alcohol added as an initiator. The deliberate addition of a predetermined amount of alcohol to the polymerisation medium is an effective way to control the molecular weight by the monomer-to-alcohol molar ratio [8]. Initiation

\footnotetext{
${ }^{*}$ Corresponding author, e-mail: Juan.RRomero@uclm.es

(C) BME-PT
} 


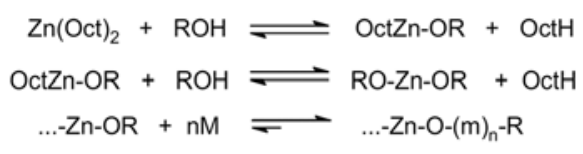

Figure 2. Initiation with zinc-alkoxide formed via carboxylate-alkoxide ligand exchange reactions. $R$ denotes $H$ or alkyl group, OctH is the 2-ethylhexanoic acid, $M$ is the lactide or glycolide molecules and $m$ is the polyester repeating unit [9]

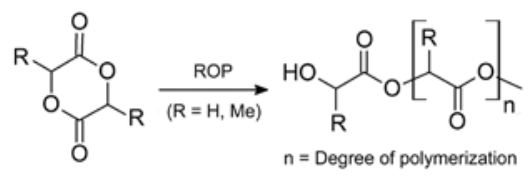

Figure 3. Ring-opening polymerization of lactones: lactide and glycolide [8]

and ROP process is shown in Figure 2 and Figure 3 $[8,9]$.

In a previous study $\mathrm{ZnOct}_{2}$ and methanol were determined as interesting catalyst and initiator respectively for the copolymerization of D,L-lactide and glycolide [10]. One of the aims of this work is to study the influence of different operational parameters such as temperature $(T)$, molar ratio monomer to catalyst ( $M C$ ratio) and molar ratio initiator to catalyst (IC ratio) and their interactions in the copolymerization process and to carry out the optimization using Response Surface Methodology (RSM) to quantify the effect of main parameters and their interactions on polymer variables such as mass conversion $(X)$ and number-average molecular weight $\left(M_{\mathrm{n}}\right)$ to produce suitable PLGA for subsequent use in drug release. Moreover, the mathematical model obtained provides a useful tool to select quickly and effortlessly the proper experimental conditions to achieve the desired properties of the polymer as a previous step in the synthesis and impregnation of biodegradable scaffolds $[11,12]$ without having to carry out complex mathematical calculations based on a rigorous theoretical model. Considering that this work represents only a practical approach in order to estimate the properties of the synthesized PLGA for a further step of impregnation, the rigorous study of the reactions that are taking place is not an end in itself (unlike other specific mechanistic or kinetic studies [10, 13-16]) so that this model of 'black box' is only a practical method to choose a set of conditions for the polymerization process.

\section{Experimental}

\subsection{Materials}

Glycolide (G) (1,4-dioxane-2,5-dione; Purac Biochem bv, The Netherlands) and D,L-lactide (L) (3,6dimethyl-1,4-dioxane-2,5-dione; Purac Biochem bv, The Netherlands) both with a purity higher than 99.5\%. Zinc octoate $\left(\mathrm{ZnOct}_{2}\right)$ (zinc (II) 2-ethylhexanoate; Nusa, Spain) with a metal content of $12 \%$. Methanol anhydre (MeOH) (SDS s.a., Spain) with purity higher than $99.85 \%$. Potassium bromide (KBr) (Sigma-Aldrich, Spain) with purity higher than $99 \%$, for FTIR measures. Tetrahydrofuran (THF) (HPLC grade; SDS s.a., Spain). 1,1,1,3,3,3hexafluor-2-propanol (Sigma-Aldrich, Spain) with purity higher than $99.8 \%$. And n-hexane (analytical grade; Brenntag Químicas s.a., Spain). All products were used as received.

\subsection{Bulk polymerizations}

All experiments were carried out in a set-up consisting on a glass stirred-tank reactor with a volume of $500 \mathrm{~mL}$ and put into a constant inert atmosphere of nitrogen. The vessel was submerged into an oil bath and heated using a hot plate. Temperature was fixed by means of a temperature controller with a sensor inside the reaction melted mixture. Samples were collected along the reaction time through an opening in the reactor cover.

In a typical experiment, the procedure took place as described in [10] using a total monomer mass of $100 \mathrm{~g}$, molar ratio D,L-lactide:glycolide (L:G) of $80: 20$ in order to get better control in the subsequent polymer degradation rate [17] and reaction time of $3 \mathrm{~h}$. All the experiments were carried out in random order to avoid any kind of residual tendency and minimize the effect of possible uncontrolled variables.

\subsection{Polymer characterizations}

\subsubsection{FTIR}

A Fourier transform infrared spectrometer (FTIR 16 PC, Perkin Elmer, Spain) was used to measure the monomers ratio in polymer. All samples were dissolved in THF or 1,1,1,3,3,3-hexafluor-2-propanol (THF-insoluble samples) with a concentration of $35 \mathrm{mg} \cdot \mathrm{mL}^{-1}$, and were applied on potassium bromide $(\mathrm{KBr}$, standard infrared grade; Sigma-Aldrich 


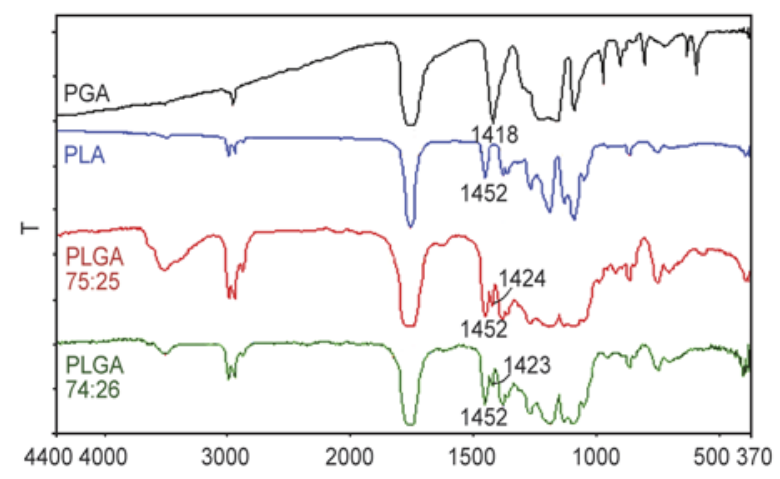

Figure 4. FTIR spectra for commercial homopolymers of glycolide, D,L-lactide, commercial PLGA 75:25 and synthesized PLGA 74:26

Química) pellets prepared by a manual hydraulic press (Perkin Elmer, Spain) and heated in oven at $70^{\circ} \mathrm{C}$ oven $30 \mathrm{~min}$ to allow the solvent to evaporate, leaving a solid film. Poly(D,L-lactide) and copolymers of PLGA standards with different molar compositions of two comonomers (Sigma-Aldrich Química) were used as reference for the estimation of the comonomer ratio in the polymer taking into account the absorption bands of $\mathrm{CH}_{2}$ group $\left(1424 \mathrm{~cm}^{-1}\right)$ and $\mathrm{CH}\left(1452 \mathrm{~cm}^{-1}\right)$. Transmittance spectra were recorded from 370 to $4400 \mathrm{~cm}^{-1}$. Figure 4 shows some examples of FTIR spectra with assigned peaks.

\subsubsection{GPC}

The molecular weight distribution was determined by gel permeation chromatography on a GPC chromatograph (Waters, Spain) equipped with two columns (Styragel HR2 and Styragel HR0.5) and a refractive index detector. Tetrahydrofuran (THF) was used as eluent at $35^{\circ} \mathrm{C}$ (flow: $1 \mathrm{~mL} \cdot \mathrm{min}^{-1}$; injection volume of $100 \mu \mathrm{L}$ ). Samples were dissolved in THF at a concentration of $1.5 \mathrm{mg} \cdot \mathrm{mL}^{-1}$ and filtered before injection (pore size: $0.45 \mu \mathrm{m}$ ). Since no specific calibration was available, all measured molecular weights are values polystyrene-equivalent values and can be used only as relative quantities.

\subsubsection{Gravimetric analysis}

A simple gravimetric analysis consisting in dissolving all monomer-impurified polymer samples, previously quantified, in THF and precipitating only the polymer by the addition of $n$-hexane was carried out in order to calculate the mass conversion of each polymerization. The solid precipitate was fil- trated under vacuum, drying in an oven at $70^{\circ} \mathrm{C}$ for a minimum of 13 hours and until constant weight.

\subsubsection{TGA}

Thermogravimetric analysis was used in order to verify the mass conversion data obtained through gravimetric method. A TGA (TA Instruments, Q600) with a refrigerated cooling system was used. Sample weights were between $3-10 \mathrm{mg}$ and the measures were run in aluminium pans until $210^{\circ} \mathrm{C}$ (PLA) or $250^{\circ} \mathrm{C}$ (PLGA) using a ramp of $40^{\circ} \mathrm{C} \cdot \mathrm{min}^{-1}$. The TGA cell was purged with nitrogen gas flow of $100 \mathrm{~mL} \cdot \mathrm{min}^{-1}$. To estimate the polymer amount, TA Universal Analysis 2000 software was utilized.

\subsection{Response surface methodology (RSM) and statistical analysis}

RSM is commonly used in the study of empirical relationships between measured responses and independent variables (also called factors), minimizing experimentation and leading to correlations which can be used for optimization purposes [18].

The effect of the operating variables in the copolymerization process (temperature, $M C$ ratio and $I C$ ratio) and their possible interactions on the mass conversion $(X)$ and number-average molecular weight $\left(M_{\mathrm{n}}\right)$ as response variables were carried out using a 23 full factorial design with two central points. The levels of each factor are indicated in Table 1 and were selected on the basis of preliminary studies of this polymerization system $[10,13-$ 15]. In order to allow a direct comparison of each variable the independent variables were normalized in the range -1 to +1 according to Equation (1):

$x_{\mathrm{i}}=\frac{2\left(X_{\mathrm{i}}-X_{\min }\right)}{\left(X_{\max }-X_{\min }\right)-1}$

where $x_{\mathrm{i}}$ is the normalized value of variable $X$ at condition $i, X_{\mathrm{i}}$ the dimensional value, and $X_{\min }$ and $X_{\max }$ represent the dimensional inferior and superior limits, respectively.

A statistical analysis was performed for these results using the commercial software Statgraphics

Table 1. Levels of factors in the experimental design

\begin{tabular}{|l|c|c|}
\hline \multicolumn{1}{|c|}{ Factor } & $\begin{array}{c}\text { Lower level } \\
(\mathbf{- 1 )}\end{array}$ & $\begin{array}{c}\text { Higher level } \\
(+\mathbf{1})\end{array}$ \\
\hline Temperature $\left[{ }^{\circ} \mathrm{C}\right]$ & 120 & 160 \\
\hline Molar ratio monomer/catalyst & 100 & 500 \\
\hline Molar ratio initiator/catalyst & 0.5 & 2 \\
\hline
\end{tabular}


5.1 Plus (Manugistics, Inc. Rockville, MD, USA). The analysis of variance (ANOVA) provided a study of the variation present in the results of experiments carried out and the test of statistical significance, $p$ value, was determined according to the total error criteria considering a confidence level of $95 \%$. The influence of a factor will be significant if the value of critical level $(p)$ is lower than 0.05 ; discarding the meaningless parameters for $p$-values over 0.05 [19]. As a result of the RSM, an empirical model encompassing all the operating variables and their binary interactions was calculated. Nevertheless, once the factors with statistical significance in mass conversion and number-average molecular weight were determined, the rest of the meaningless information was deleted from this model, obtaining new equations, for $X$ and $M_{\mathrm{n}}$, which fitted the experimental data representing much correctly their scientific meaning and avoiding fitting terms for discarded variables or their interactions.

\section{Results and discussion}

As commented before, the effect of the operating variables ( $T, M C$ ratio and $I C$ ratio) and their possible interactions on the mass conversion $(X)$ and number-average molecular weight $\left(M_{\mathrm{n}}\right)$ were studied using a 23 full factorial design. The standard experimentation matrix is shown in Table 2. Columns 2 to 4 give the variable levels coded in the dimensionless coordinate while as columns 5 to 7 give the dimensional variable levels. Table 2 also shows the experimental values obtained for the selected responses (columns 8, 9, 11 and 12) together with theoretical number-average molecular weight (column 10) supposing activity of both active centres of $\mathrm{Zn}(\mathrm{Oct})_{2}$ and calculated according to the following Equation (2) [15]:

$M_{\text {theoretical }}=\frac{1}{2} \cdot \frac{M_{\mathrm{n}}}{C} \cdot \frac{X[\%]}{100} \cdot M_{\text {weighted }}$

where $M / C$ is the molar ratio monomer to catalyst, $M_{\mathrm{n}}$ is the experimental number-average molecular weight, $X$ is the total monomer conversion and $M_{\text {weighted }}$ is a weighted molecular weight for a pseudo-monomer formed by a mixture of both comonomers, assuming that monomer mixture composition does not change along the reaction (80:20 for D,L-lactide and glycolide, respectively). So, for a conversion of $100 \% M_{\text {theoretical }}$ should be 6900 approximately.

\subsection{Statistical analysis in RSM: ANOVA test and evaluation of the effect of curvature}

The analysis of main effects and their interactions for the chosen responses are shown in Table 3. Statistically significant effects are underlined according to $p$-values calculated.

In order to obtain correlations to predict the responses values along the interval studied, it is necessary to evaluate the curvature and the effect of curvature. Curvature $(C)$ can be calculated as the difference between the mean value of the response analyzed considering all the experimental points $\left(y_{\mathrm{m}}\right)$ and the mean value of the response analyzed considering only the central points $\left(y_{\mathrm{mCP}}\right)$. Effect of curvature $(E C)$ is obtained through the Equation (3):

$E C=t \cdot s \cdot \sqrt{\frac{1}{N}+\frac{1}{r}}$

Table 2. Experimental matrix and results for the full $2^{3}$ factorial design ${ }^{\mathrm{a}}$

\begin{tabular}{|c|c|c|c|c|c|c|c|c|c|c|c|}
\hline Run & $\begin{array}{c}\mathbf{T} \\
{\left[{ }^{\mathbf{}} \mathbf{C}\right]}\end{array}$ & $\mathbf{M} / \mathbf{C}$ & $\mathbf{I} / \mathbf{C}$ & $\begin{array}{c}\mathbf{T} \\
{\left[{ }^{\mathbf{}} \mathbf{C}\right]}\end{array}$ & $\mathbf{M} / \mathbf{C}$ & $\mathbf{I} / \mathbf{C}$ & $\mathbf{X}$ & $\begin{array}{c}\mathbf{M} \\
{[\mathbf{g} / \mathbf{m o l}]}\end{array}$ & $\begin{array}{c}\mathbf{M}_{\text {theoretical }}^{\mathbf{b}} \\
{[\mathbf{g} / \mathbf{m o l}]}\end{array}$ & $\mathbf{P D I}^{\mathbf{c}}$ & $\begin{array}{c}\mathbf{L}: \mathbf{G} \\
{[\mathbf{\%}]}\end{array}$ \\
\hline 1 & -1 & -1 & -1 & 120 & 100 & 0.5 & 0.65 & 13700 & 4500 & 1.67 & $72: 28$ \\
\hline 2 & +1 & -1 & -1 & 160 & 100 & 0.5 & 0.87 & 22600 & 6000 & 1.61 & $80: 20$ \\
\hline 3 & -1 & +1 & -1 & 120 & 500 & 0.5 & 0.87 & 12900 & 29500 & 1.66 & $71: 29$ \\
\hline 4 & +1 & +1 & -1 & 160 & 500 & 0.5 & 0.97 & 18600 & 33400 & 1.66 & $77: 23$ \\
\hline 5 & 0 & 0 & 0 & 140 & 250 & 1 & 0.80 & 15500 & 13600 & 1.64 & $71: 29$ \\
\hline 6 & -1 & -1 & +1 & 120 & 100 & 2 & 0.69 & 11100 & 4700 & 1.53 & $69: 31$ \\
\hline 7 & +1 & -1 & +1 & 160 & 100 & 2 & 0.98 & 18000 & 6700 & 1.67 & $74: 26$ \\
\hline 8 & -1 & +1 & +1 & 120 & 500 & 2 & 0.40 & 3600 & 13500 & 1.49 & $61: 39$ \\
\hline 9 & +1 & +1 & +1 & 160 & 500 & 2 & 0.99 & 23600 & 33900 & 1.87 & $73: 27$ \\
\hline 10 & 0 & 0 & 0 & 140 & 250 & 1 & 0.78 & 14900 & 13400 & 1.85 & $73: 27$ \\
\hline
\end{tabular}

${ }^{a}$ Conditions for all experiments: Total monomers mixture weight, $100 \mathrm{~g}$; molar ratio $L: G=80: 20$; stirring rate, $100 \mathrm{~N} ; t=3 \mathrm{~h}$.

${ }^{b} \mathrm{M}_{\text {theoretical }}$ is the theoretical number-average molecular weight of PLGA and it has been calculated using Equation (2).

'PDI is the polydispersity index $\left(P D I=\frac{M_{\mathrm{w}}}{M_{\mathrm{n}}}\right)$, necessary together $M_{\mathrm{w}}$ or $M_{\mathrm{n}}$ to fully describe the morphology of the polymer chains in
the molecular weight distribution. 
Table 3. Estimated effects, interactions and ANOVA analysis from $2^{3}$ factorial design for the polymerization system

\begin{tabular}{|l|r|r|r|c|}
\hline \multirow{2}{*}{ Factor of interaction } & \multicolumn{2}{|c|}{$\mathbf{X}$} & \multicolumn{2}{c|}{$\mathbf{M}_{\mathbf{n}}$} \\
\cline { 2 - 5 } & Effects ( $\pm \mathbf{s})$ & p-Value & Effects $( \pm \mathbf{s})$ & p-Value \\
\hline$T$ & $0.3( \pm 0.014)$ & 0.0019 & $10375( \pm 424.264)$ & 0.0042 \\
\hline$M / C$ & $0.011689( \pm 0.014)$ & 0.4603 & $-1575.47( \pm 424.264)$ & 0.1433 \\
\hline$I / C$ & $-0.011689( \pm 0.014)$ & 0.0297 & $-2742.29( \pm 424.264)$ & 0.0545 \\
\hline$T \cdot M / C$ & $0.045( \pm 0.014)$ & 0.0740 & $2475( \pm 424.264)$ & 0.0670 \\
\hline$T \cdot M / C$ & $0.14( \pm 0.014)$ & 0.0085 & $3075( \pm 424.264)$ & 0.0450 \\
\hline$M / C \cdot M / C$ & $-0.150563( \pm 0.014)$ & 0.0073 & $691.823( \pm 424.264)$ & 0.4129 \\
\hline$T \cdot M / C \cdot I / C$ & $0.105( \pm 0.014)$ & 0.1490 & $4075( \pm 424.264)$ & 0.0664 \\
\hline
\end{tabular}

Table 4. Curvature and effect of curvature calculated for both responses

\begin{tabular}{|l|c|c|c|c|}
\hline & $\mathbf{y}_{\mathbf{m}}$ & $\mathbf{y}_{\mathbf{m C P}}$ & $\begin{array}{c}\text { Curvature } \\
\text { (C) }\end{array}$ & $\begin{array}{c}\text { Effect of curvature } \\
\text { (EC) }\end{array}$ \\
\hline$X$ & 0.8025 & 0.79 & 0.0125 & 0.0706 \\
\hline$M_{\mathrm{n}}$ & 15512.5 & 15200 & 312.5 & 2117.7129 \\
\hline
\end{tabular}

where $t$ is the $t$ parameter from the Student's t-distribution, $s$ is the standard deviation, $N$ is the number of experiments and $r$ is the number of central points.

According to Table 4 the effect of curvature was not significant for any response. The lack of significance of the curvature indicates the validity of the pure design in the experimental range analyzed and shows that linear terms and their interactions are enough to describe the responses studied and, consequently, quadratic terms are not necessary.

\subsection{Mass conversion}

From results in Table 2 and using RSM (Table 3), the only factors affecting mass conversion are $T, I C$ ratio, the binary interaction $T-I C$ ratio and the binary interaction $M C-I C$ ratio.

It can be concluded from the RSM that $T$ is the main effect and it is positive along the interval. Obviously the polymerization reaction rate follows the Arrhenius Law and conversion increases for the same reaction time at higher temperatures. For that reason, in most of the experiments conversions above 0.95 are reached at $160^{\circ} \mathrm{C}$. However, for those experiments at $120^{\circ} \mathrm{C}$ conversion falls down because the advance of the polymerization is much slower and conversion is still quite low at three hours.

The $I C$ ratio had a negative effect according to Table 3. It can be explained taking into account that the initiator acts also as chain transfer agent. Its presence in the media favours the occurrence of termination reactions (chain transfer) which cuts the growth of the polymer chain even though a significant quantity of monomer remains in reaction medium. The observed effect is that the conversion decreases markedly. An excess of a chain transfer agent like methanol in the medium [15], which corresponds with $I C$ ratio $=2$ produces an early deceleration of the conversion growth.

Since both effects are opposed and a binary interaction $T-I C$ ratio exists (Figure $5 \mathrm{a}$ ), the combined effect of both produces different results depending on the considered level. As previously commented, temperature is the main effect according to RSM analysis. For that reason at the higher temperature level its effect on conversion prevail over the $I C$ ratio because although there is an excess of methanol (initiator) in the reaction medium, the conversion reaches elevated values in a very short period of time. Nevertheless, for the low $T$ level, the reaction rate is not fast enough to stand out its effect over higher values of $I C$ ratio. As a result, the chain transfer reactions become more noticeable than polymerization reaction and the mass conversion
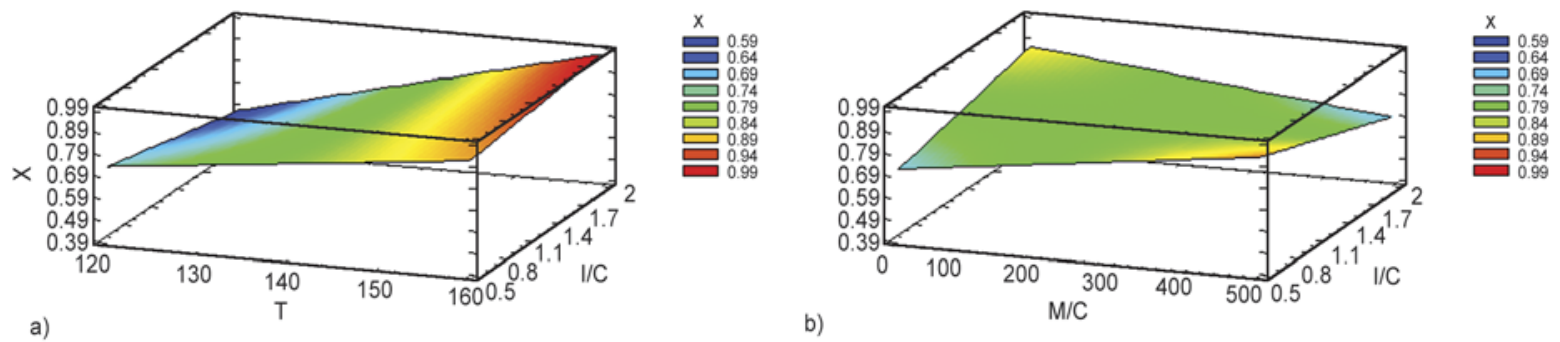

Figure 5. Response surfaces plot showing the combined effect $T-I C$ ratio (a) and $M C-I C$ ratios (b) on the mass conversion as a result of RSM analysis 
decreases when $I C$ ratio increases at this temperature.

Moreover, a binary interaction between $M C$-IC ratios also exists. In this case, the $M C$ ratio has not signification and the results must be analyzed together $I C$ ratio. Figure $5 \mathrm{~b}$ shows the combined effect of both variables over the conversion. Mainly, the effect of a decrease in $M C$ ratio, and therefore an increase in the quantity of catalyst added to the system, is an increase of conversion since polymerization rate is accelerated. Consequently, the effect is similar to previous interaction: at low $M C$ ratios (high amount of catalyst in reaction medium) its effect is stronger than the effect of chain transference, so the mass conversion increases in all the interval of $I C$ ratios. When $M C$ ratio is high (low amount of catalyst) the chain growth is not so fast, so high values of $I C$ ratio (large amounts of methanol which acts a chain transfer agent) produce a growth ineffective an earlier step of polymerization and as a consequence the mass conversion decreases.

As described before above, according to Table 4 the effect of curvature was no significant, indicating the validity of pure fractional design in the experimental range analyzed, so that second-order models were not necessary to describe the process. Equation (4) that relates the mass conversion to the independent variables can be expressed in the following terms:

$$
\begin{aligned}
& X=-0.253+6.542 \cdot 10^{-3} \cdot T+2.932 \cdot 10^{-3} \cdot \frac{M}{C} \\
& +0.184 \cdot \frac{I}{C}-1.625 \cdot 10^{-5} \cdot T \cdot \frac{M}{C}-5.833 \cdot 10^{-4} \cdot T \cdot \frac{I}{C} \\
& -2.952 \cdot 10^{-3} \cdot \frac{M}{C} \cdot \frac{I}{C}+1.750 \cdot 10^{-5} \cdot T \cdot \frac{M}{C} \cdot \frac{I}{C}
\end{aligned}
$$

where the values of all variables are specified in their original units.

\subsection{Number-average molecular weight}

According to data shown in Table 2 and using RSM (Table 3), the more influential factor on the molecular weight is $T$ together to the binary interaction $T$ $I C$ ratio. In this case, the effect of temperature is also positive according to Arrhenius equation due to an increase in the polymerization rate promotes the chains growth and, consequently, their molecular weight.

Analogously to the previous section and according to Figure 6, the binary interaction $T-I C$ ratio has a

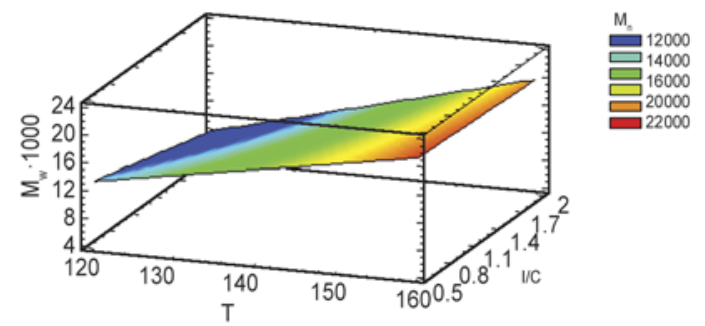

Figure 6. Response surface plot showing the combined effect of temperature together $I C$ ratio on the number-average molecular weight

similar positive effect in $M_{\mathrm{n}}$ and $X$ during the polymerization process. Comparing Figure 6 with Figure $5 \mathrm{a}$, this similarity can be easily understood taking into account that a larger extension of the polymerization can be evaluated through the mass conversion (based on the ratio between the amount of initiated chains in relation to the amount of unreacted monomer) or the molecular weight of the synthesized polymer. At higher temperatures its effect is more noticeable than the action of methanol as chain transfer agent even when a large amount is added to the system. Therefore, $M_{\mathrm{n}}$ is always increasing in all the interval of $I C$ ratios. At low temperature, the tendency is the same although less marked that for the case of mass conversion: reaction rate is slower due to the Arrhenius Law and consequently any reaction of chain transfer produced by methanol (especially at higher $I C$ ratios) stops the polymerization. In this case, the decreasing of $M_{\mathrm{n}}$ is minor and for that reason the slope of the response surface is less pronounced.

As it can be observed in Table 2, the experimental $M_{\mathrm{n}}$ values resulted quite low in comparison to theoretical $M$ in experiments with $M C$ ratio of 500. A possible explanation for these low molecular weights could be in the few quantity of catalyst employed that limits the conversion of zinc octoate into zinc alkoxide for the initiation reaction (Figure 2). This fact generates a competition between this reaction and other secondary reactions (transesterification, interesterification) that could be produced even by impurities or humidity traces in the polymerization mixture [20]. It would justify the negative influence of $M C$ ratio although it has not signification in the statistical analysis. On the contrary, for experiments carried out with $M C$ values of 100 the quantity of catalyst is not a limiting reagent in the reaction. In this case, experimental $M_{\mathrm{n}}$ values are significantly larger than theoretical ones which means that only 
takes place the substitution of one carbolixate group from $\mathrm{Zn}(\mathrm{Oct})_{2}$ for one methoxide group of initiator [21].

Due to the lack of significance of the effect of curvature, the fitting of data to a first-order model gave as a result an empirical relationship between the dependent variable $M_{\mathrm{n}}$ and the independent variables described by the Equation (5):

$$
\begin{aligned}
& M_{\mathrm{n}}=-21392.400+292.125 \cdot T+68.720 \cdot \frac{M}{C} \\
& +11655 \cdot \frac{I}{C}-0.540 \cdot T \cdot \frac{M}{C}-101.250 \cdot T \cdot \frac{I}{C} \\
& -92.777 \cdot \frac{M}{C} \cdot \frac{I}{C}+0.679 \cdot T \cdot \frac{M}{C} \cdot \frac{I}{C}
\end{aligned}
$$

where the values of all variables are specified in their original units.

\subsection{Equations fitting according the significant effects and comparison of predicted parameters with experimental values}

Equations (4) and (5) have been considered as a result of applying the RSM. Once they were calculated, the non-influential effects were deleted in them and consequently changing into Equations (6) and (7) respectively:

$$
\begin{aligned}
& X=-0.438+1.667 \cdot 10^{-3} \cdot T-0.551 \cdot \frac{I}{C} \\
& +4.667 \cdot 10^{-3} \cdot T \cdot \frac{I}{C}-5.020 \cdot 10^{-4} \cdot T \cdot \frac{M}{C} \cdot \frac{I}{C} \\
& M_{\mathrm{n}}=-2925+131.250 \cdot T-14350 \cdot \frac{I}{C} \\
& +102.500 \cdot T \cdot \frac{I}{C}
\end{aligned}
$$

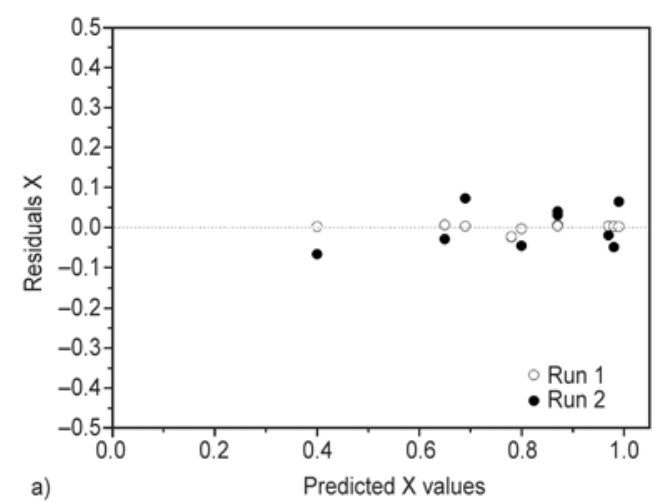

These new equations gave different predicted values which were compared with the experimental ones according to Figure 7. Residuals of values given by both models versus fitted values were graphically represented. As it can be appreciated, the values predicted with the Run 2 fitted the experimental ones reasonably (the best accuracy was obtained with the mass conversion model) and additionally the scientific meaning with respect to the Run 1 was improved. If the residuals of both Runs are analyzed, it can be appreciated that the variability of the simplified model is slightly greater although the tendency continues to be linear, the residuals are quite symmetrical and there is no heteroscedasticity. Therefore, the acceptance of the model has been confirmed.

\subsection{Global optimization of the polymerization process}

From previous results, the optimization of polymerization process for variables $X$ and $M_{\mathrm{n}}$ cannot be performed in a separated way due to different tendencies in the effects of the studied parameters depending on the range values. For that reason it is necessary to optimize the values of $T, M C$ ratio and $I C$ ratio in order to select the best operation conditions in the experimental range analyzed.

Regarding to the mass conversion of polymer, a high value is desired since it minimizes the quantity of unreacted monomer as potential impurity which could perturb the drug release process. The appropriate conditions which achieve this criterion included to work at high temperature $\left(160^{\circ} \mathrm{C}\right)$ and to use values of $M C$ and $I C$ ratios which do not promote the competition of the initiation step of polymerization with other ones and do no generate an

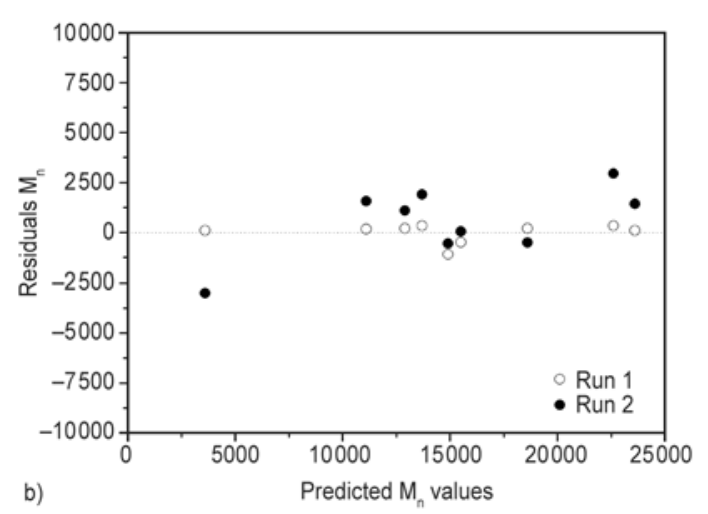

Figure 7. Graphical representation of residuals given by both models versus fitted values for: (a) $X$; (b) $M_{\mathrm{n}}$. Empty circles corresponds to the first run of the model and filled circles corresponds to the second run 
excess of methanol that acts as a chain transfer agent. Namely, values of 100 and 0.5 for $M C$ ratio and $I C$ ratio respectively.

However, in relation to $M_{\mathrm{n}}$ and according not only to the specific polymer characteristics but their subsequent use as biodegradable scaffold in controlled drug release, it is not necessary to achieve its maximum value. Authors [22-25] use a wide variety of values of PLGA molecular weight for this purpose, although molecules of PLGA with molecular weight values around 20000 seem to be suitable for their use in controlled drug release [26, 27]. So as long as a temperature of $160^{\circ} \mathrm{C}$ is selected, this target value is reached and any value of $M C$ ratio or $I C$ ratio would be appropriate.

Finally, in order to determine globally the best operating conditions, it is necessary to consider copolymer composition because it plays a relevant role due to its influence to modulate the degradation rate of the scaffold [17]. For this reason, this variable should be taken into account. According to literature [22, 28, 29], L:G molar compositions of PLGA of 50:50, 85:15 and 75:25 are widely used and ratios around $75: 25$ are highly desirables since they achieve high control on the degradation rates [17]. From Table 2, the experimental conditions which accomplish all the previous requirements of mass conversion, number-average molecular weight and copolymer composition are: $160^{\circ} \mathrm{C}, M C$ ratio of 100 and $I C$ ratio of 2 , and they can be determined as the optimal polymerization conditions.

\section{Conclusions}

RSM has been used in this work to screen variables affecting copolymerization in bulk of D,L-lactide and glycolide, to estimate the main effects caused by these variables individually and by their interaction and to develop an empirical model to optimize the resultant copolymer in order to get the best option for its subsequent use as tissue scaffold and drug release device. This model provides a practical tool in order to avoid a rigorous mechanistic study of the polymerization in this preliminary step of the research.

The regression models proposed to predict mass conversion $(X)$ and number-average molecular weight $\left(M_{\mathrm{n}}\right)$ were found to fit experimental data properly after identified the experimental variables statistically significant and simplified the model only using them.
Temperature of $160^{\circ} \mathrm{C}$ and molar $M C$ ratio and $I C$ ratio of 100 and 2 respectively were selected as the optimal experimental variables in order to maximize the value of $X$ and produce a relatively high $M_{\mathrm{n}}$, producing the appropriate PLGA for the subsequent stages of the synthesis of biodegradable scaffolds.

\section{Acknowledgements}

Financial support from JCCM project PBI05-014 is gratefully acknowledged.

\section{References}

[1] Davis S. S., Illum L., Stolnik S.: Polymers in drug delivery. Current Opinion in Colloid and Interface Science, 1, 660-666 (1996).

DOI: $10.1016 / \mathrm{S} 1359-0294(96) 80105-1$

[2] Gilding D. K., Reed A. M.: Biodegradable polymers for use in surgery-polyglycolic/poly(actic acid) homoand copolymers: 1. Polymer, 20, 1459-1464 (1979). DOI: 10.1016/0032-3861(79)90009-0

[3] Temenoff J. S., Mikos A. G.: Review: Tissue engineering for regeneration of articular cartilage. Biomaterials, 21, 431-440 (2000).

DOI: $10.1016 / \mathrm{S} 0142-9612(99) 00213-6$

[4] Okada M.: Chemical syntheses of biodegradable polymers. Progress in Polymer Science, 27, 87-133 (2002). DOI: 10.1016/S0079-6700(01)00039-9

[5] Kricheldorf H. R.: Syntheses and application of polylactides. Chemosphere, 43, 49-54 (2001).

DOI: $10.1016 / \mathrm{S} 0045-6535(00) 00323-4$

[6] Kricheldorf H. R., Bornhorst K., Hachmann-Thiessen H.: Bismuth(III) $n$-hexanoate and tin(II) 2-ethylhexanoate initiated copolymerizations of $\varepsilon$-caprolactone and L-lactide. Macromolecules, 38, 5017-5024 (2005). DOI: $\underline{10.1021 / \mathrm{ma} 0478730}$

[7] Kowalski A., Duda A., Penczek S.: Kinetics and mechanism of cyclic esters polymerization initiated with tin(II) octoate, 1. Polymerization of $\varepsilon$-caprolactone. Macromolecular Rapid Communications, 19, 567-572 (1998).

DOI: 10.1002/(SICI)1521-3927(19981101)19:11<567 $\because$ AID-MARC567>3.0.CO;2-T

[8] Jerôme R., Lecomte P.: New developments in the synthesis of aliphatic polyesters by ring-opening polymerisation. in 'Biodegradable polymers for industrial applications' (ed.: Smith R.). Woodhead Publishing Limited, Cambridge, Vol 1, 77-106 (2005).

[9] Kowalski A., Libiszowski J., Majerska K., Duda A., Penczek S.: Kinetics and mechanism of $\varepsilon$-caprolactone and L,L-lactide polymerization coinitiated with zinc octoate or aluminum acetylacetonate: The next proofs for the general alkoxide mechanism and synthetic applications. Polymer, 48, 3952-3960 (2007). DOI: $10.1016 /$ j.polymer.2007.05.007 
[10] Mazarro R., Cabezas L. I., de Lucas A., Gracia I., Rodríguez J. F.: Study of different catalysts and initiators in bulk copolymerization of D,L-lactide and glycolide. Journal of Macromolecular Science Part A: Pure and Applied Chemistry, 46, 1049-1059 (2009). DOI: $10.1080 / 10601320903252090$

[11] Cabezas L. I., Fernández V., Gracia I., de Lucas A., Rodríguez J. F.: Production of biodegradable porous scaffolds impregnated with indomethacin in supercritical $\mathrm{CO}_{2}$. Journal of Supercritical Fluids, 63, 155-160 (2012).

DOI: 10.1016/j.supflu.2011.12.002

[12] Cabezas L. I., Gracia I., García M. T., de Lucas A., Rodríguez J. F.: Production of biodegradable porous scaffolds impregnated with 5-fluorouracil in supercritical $\mathrm{CO}_{2}$. Journal of Supercritical Fluids, 80, 1-8 (2013).

DOI: $10.1016 /$ j.supflu.2013.03.030

[13] Mazarro R., de Lucas A., Gracia I., Rodríguez J. F.: Copolymerization of D,L-lactide and glycolide in supercritical carbon dioxide with zinc octoate as catalyst. Journal of Biomedical Materials Research Part B: Applied Biomaterials, 85, 196-203 (2008). DOI: $10.1002 / \mathrm{jbm} \cdot$ b.30936

[14] Mazarro R., de Lucas A., Gracia I., Rodríguez J. F.: Kinetic study of D,L-lactide and glycolide homopolymerizations by differential scanning calorimetry. Macromolecular Chemistry and Physics, 209, 818-824 (2008). DOI: 10.1002/macp.200700527

[15] Mazarro R., de Lucas A., Cabezas L. I., Gracia I., Rodríguez J. F.: Influence of the operative conditions on the characteristics of poly(D,L-lactide-co-glycolide) synthesized in supercritical carbon dioxide. Macromolecular Symposia, 287, 111-118 (2010). DOI: $10.1002 /$ masy.201050116

[16] Mazarro R., Gracia I., Rodríguez J. F., Storti G., Morbidelli M.: Kinetics of the ring-opening polymerization of D,L-lactide using zinc (II) octoate as catalyst. Polymer International, 61, 265-273 (2012). DOI: 10.1002/pi.3182

[17] Miller R. A., Brady J. M., Cutright D. E.: Degradation rates of oral resorbable implants (polylactates and polyglycolates): Rate modification with changes in PLA/PGA copolymer ratios. Journal of Biomedical Materials Research, 11, 711-719 (1977). DOI: $10.1002 / \mathrm{jbm} .820110507$

[18] Box J. E. P., Hunter W. G., Hunter J. S.: Statistics for experimenters: An introduction to design, data analysis and model building. Wiley, New York (1978).

[19] Box J. E. P., Hunter W. G., Hunter J. S.: Statistics for experimenters: Design, discovery and innovation. Wiley, New Jersey (2005).
[20] Libiszowski J., Kowalski A., Duda A., Penczek S.: Kinetics and mechanism of cyclic esters polymerization initiated with covalent metal carboxylates, 5. Endgroup studies in the model $\varepsilon$-caprolactone and L,Ldilactide/Tin(II) and zinc octoate/butyl alcohol systems. Macromolecular Chemistry and Physics, 203, 1694-1701 (2002).

DOI: 10.1002/1521-3935(200207)203:10/11<1694:: AID-MACP1694>3.0.CO;2-J

[21] Biela T., Kowalski A., Libiszowski J., Duda A., Penczek S.: Progress in polymerization of cyclic esters: Mechanisms and synthetic applications. Macromolecular Symposia, 240, 47-55 (2006).

DOI: $10.1002 /$ masy. 200650807

[22] Holy C. E., Dang S. M., Davies J. E., Shoichet M.: S. In vitro degradation of a novel poly(lactide-co-glycolide) 75/25 foam. Biomaterials, 20, 1177-1185 (1999). DOI: $10.1016 / \mathrm{S} 0142-9612(98) 00256-7$

[23] Miyajima M., Koshika A., Okada J., Kusai A., Ikeda M.: The effects of drug physico-chemical properties on release from copoly (lactic/glycolic acid) matrix. International Journal of Pharmaceutics, 169, 255-263 (1998). DOI: $10.1016 / \mathrm{S} 0378-5173(98) 00133-1$

[24] Siegel S. J., Kahn J. B., Metzger K., Winey K. I., Werner K., Dan N.: Effect of drug type on the degradation rate of PLGA matrices. European Journal of Pharmaceutics and Biopharmaceutics, 64, 287-293 (2006). DOI: 10.1016/j.ejpb.2006.06.009

[25] Dorta M. J., Santoveña A., Llabrés M., Fariña J. B.: Potential applications of PLGA film-implants in modulating in vitro drugs release. International Journal of Pharmaceutics, 248, 149-156 (2002). DOI: $10.1016 / \mathrm{S} 0378-5173(02) 00431-3$

[26] Schliecker G., Schmidt C., Fuchs S., Wombacher R., Kissel T.: Hydrolytic degradation of poly(lactide-coglycolide) films: Effect of oligomers on degradation rate and crystallinity. International Journal of Pharmaceutics, 266, 39-49 (2003). DOI: $10.1016 / \mathrm{S} 0378-5173(03) 00379-\mathrm{X}$

[27] Kou J. H., Emmett C., Shen P., Aswani S., Iwamoto T., Vaghefi F., Cain G., Sanders L.: Bioerosion and biocompatibility of poly $(d, l$-lactic-co-glycolic acid) implants in brain. Journal of Controlled Release, 43, 123-130 (1997). DOI: 10.1016/S0168-3659(96)01477-0

[28] Sheridan M. H., Shea L. D., Peters M. C., Mooney D. J.: Bioabsorbable polymer scaffolds for tissue engineering capable of sustained growth factor delivery. Journal of Controlled Release, 64, 91-102 (2000). DOI: 10.1016/S0168-3659(99)00138-8

[29] Lu L., Peter S. J., Lyman M. D., Lai H-L., Leite S. M., Tamada J. A., Uyama S., Vacanti J. P., Langer R., Mikos A. G.: In vitro and in vivo degradation of porous poly(DL-lactic-co-glycolic acid) foams. Biomaterials, 21, 1837-1845 (2000). DOI: $\underline{10.1016 / \mathrm{S} 0142-9612(00) 00047-8}$ 